Golding J, Limerick S, Macfarlane A. Sudden infant death: Patterns, pu 2 les and problems. Shepton Mallet: Open Books, 1985.

10 Southall DP, Samuels MP. Reducing risks in the sudden infant death syndrome. $B M F$ 1 1992;304:265.

1 Medicine and culture [editorial]. Lancet 1991;337:1012.

2 McKenna JJ. Evolution and sudden infant death syndrome (SIDS). Part I. Infant responsivity to parental contact. Human Nature 1990;1:145-77

13 McKenna JJ. Evolution and sudden infant death syndrome (SIDS). Part II. Why human infants? Human Nature 1990;1:179-206.

14 McKenna JJ, Mosko S. Evolution and Sudden Infant Death Syndrome (SIDS). Part III. Infant arousal and parent-infant co-sleeping. Human Nature 1990;1:291-330.

15 McKenna JJ, Mosko S, Dungy C, McAninch J. Sleep and arousal patterns of co-sleeping human mother/infant pairs: a preliminary physiological study co-sleeping human mother/infant pairs: a preliminary physiological study
with implications for the study of sudden infant death syndrome. Am f Phy's with implications for the stuc

16 Janes CR, Stall R, Gifford R. Anthropology and epidemiology: interdisciplinary approaches to the study of health and disease. Dordrecht: D Reidel, 1986.
17 Arkinson P. The clinical experience: an ethnography of medical education. Farnborough: Gower, 1981

18 Alam F. Salience of homeland: societal poliarization within the Bangladeshi population in Britain. Coventry: Centre for Research in Ethnic Relations, University of Warwick, 1988

9 Office of Population Censuses and Surveys. County Monitor 1991 Census, South Glamorgan. London: HMSO, 1991

20 Glaser BG and Strauss AL. The Discovery of grounded theory: strategies for qualitative research. Chicago: Aldine, 1967.

21 Oakley A. From here to maternity: becoming a mother. Harmondsworth: Penguin, 1981

22 Farooqi S, Perry IJ, Beevers DG. Ethnic differences in sleeping position and in risk of cot death. Lancet 1991;338:1455.

23 Bergman A. The discovery of sudden infant death syndrome: lessons in the practice of political medicine. New York: Praeger, 1986.

(Accepted 14 October 1992)

\title{
Investigation of inheritance of chronic inflammatory bowel diseases by complex segregation analysis
}

\author{
Marianne Orholm, Lennart Iselius, Thorkild I A Sørensen, Pia Munkholm, Ebbe Langholz, \\ Vibeke Binder
}

\section{Abstract}

Objective-To investigate the mode of inheritance of ulcerative colitis and Crohn's disease by complex segregation analysis.

Design-Cross sectional population based survey of familial occurrence of chronic inflammatory bowel disease.

Setting-Population of the Copenhagen county in 1987.

Subjects-662 patients in whom inflammatory bowel disease had been diagnosed before 1979, of whom $637(96 \%)$ provided adequate information. Of 504 patients with ulcerative colitis, 54 had 77 relatives with ulcerative colitis and of 133 patients with Crohn's disease, five had seven relatives with Crohn's disease.

Main outcome measures-Patterns of segregation of either disease as assessed by complex segregation analysis performed with the computer program POINTER.

Medical

Gastroenterological Department C, Herlev Hospital, University of Copenhagen, Copenhagen, Denmark

Marianne Orholm, senior registrar

Pia Munkholm, registrar Ebbe Langholz, research fellow

Vibeke Binder, chief physician

Department of Surgery, Karolinska Hospital, Stockholm, Sweden Lennart Iselius, registrar

Institute of Preventive Medicine, Copenhagen Health Services,

Copenhagen Municipal Hospital, Copenhagen Thorkild I A Sørensen, professor

Correspondence to: Dr M Orholm, Department of Infectious Diseases 7721,

Rigshospitalet,

Tagensvej 20, DK-2200

Copenhagen N, Denmark inheritance further we performed a complex segregation analysis. ${ }^{7}$ This allows testing of hypotheses of inheritance of a major dominant, additive, or recessive gene and multifactorial genetic or environmental inheritance.

\section{Patients and methods}

The county of Copenhagen has about 500000 inhabitants, about $10 \%$ of the total Danish population. The annual incidence of ulcerative colitis and Crohn's disease in this region was estimated for the years 1962 to 1978 and the prevalences on 31 December 1978 were calculated. ${ }^{8}$ Of the 694 patients with prevalent disease in 1978, 662 were alive on 1 January 1987. These patients served as probands in the present study.

The diagnostic criteria for ulcerative colitis and Crohn's disease in the probands have been described. ${ }^{68}$ Briefly, the diagnosis of ulcerative colitis was based on the presence of at least three of the following four criteria: a typical history of diarrhoea; stools containing blood and pus, or both, for more than one week or in repeated episodes; a typical sigmoidoscopic appearance, with granulated friable mucosa or ulcerations, or both; histological or cytological signs of inflammation; and radiological or colonoscopic signs of ulcerations with or without spiculation or granulation of the inner surface of the colon proximal to the rectum. The diagnosis of Crohn's disease was based on the presence of at least two of the following four criteria: a history of diarrhoea lasting more than three months; radiological findings of typical stenoses and prestenotic dilatation in the small bowel or segments with a cobblestone appearance in the large bowel; histological findings of transmural lymphocytic infiltration or occurrence of epithelial granulomas with giant cells of Langhans' type, or both; and the occurrence of fistulas or abscesses, or both, in a region of intestinal disease. Before either ulcerative colitis or Crohn's disease was diagnosed infectious and neoplastic diseases had to be ruled out.

In 10 patients who had met the criteria for ulcerative colitis in 1978 the diagnosis was later changed to Crohn's disease; the diagnosis was changed to ulcerative colitis in three patients who had originally had Crohn's disease diagnosed. The diagnoses presented in this study were those made in 1987-that is, the conclusion reached after a median $15(9-49)$ years of observation.

We sent a questionnaire requesting complete family history to each patient. Adequate information was 
obtained from 637 of the 662 patients (96\%): 504 patients with ulcerative colitis and 133 patients with Crohn's disease. ${ }^{\circ}$

We telephoned all patients who stated that actual or possible inflammatory bowel disease was present in one or more family members and obtained the names and dates of birth of the affected family members. The diagnosis was confirmed or excluded by applying the criteria mentioned above to the relatives' medical records from hospitals or private physicians. Fifty four probands with ulcerative colitis had 77 relatives with the same disease (46 first degree relatives, 22 second degree, nine third or fourth degree). Two of these 54 probands had two relatives with Crohn's disease, and another five probands had seven relatives with Crohn's disease. Five probands with Crohn's disease had seven relatives with that disease (four first degree, three second degree), and four Crohn's disease probands had six relatives with ulcerative colitis. All first degree relatives of the affected family members were characterised with regard to sex and year of birth (and death). The occurrence of multiple probands in the families has been described. ${ }^{6}$

Patients who refused to participate, who did not answer the letters or telephone calls, or who were adopted or unable to give information about bowel disease in their relatives were not included in the segregation analysis, nor were children younger than 8 years of age.

\section{STATISTICAL ANALYSIS}

The complex segregation analysis is based on the distribution of the disease in nuclear families (parents and their offspring). Each pedigree ascertained on the basis of the probands can contain one or more nuclear families. The 504 ulcerative colitis probands belonged to 495 pedigrees, which were split into 872 nuclear families with 2414 children; the 133 Crohn's disease probands belonged to 133 pedigrees, which were split into 209 nuclear families with 549 children.

The analysis required that any relative with Crohn's disease in the ulcerative colitis group was considered to be normal and vice versa in the Crohn's disease group. In the Crohn's disease group any person dying before 1940 was coded as "unknown" since Crohn's disease was not described until 1932. Table I gives the combinations of phenotypes among the parents-the mating types.

TABLE I-Distribution of 872 ulcerative colitis nuclear families and 209 Crohn's disease nuclear families by ascertainment and mating type

\begin{tabular}{lrrrc}
\hline & \multicolumn{5}{c}{ Mating type* $^{*}$} \\
\cline { 2 - 5 } Type of selection & $\mathrm{N} \times \mathrm{N}$ & $\mathrm{N} \times \mathrm{A}$ & $\mathrm{N} \times \mathrm{U}$ & $\mathrm{U} \times \mathrm{U}$ \\
\hline Ulcerative colitis: & & 375 & & \\
$\quad$ Complete & & & & \\
$\quad$ Incomplete & 464 & 20 & 10 & 3 \\
Crohn's disease: & & 80 & & \\
$\quad$ Complete & 122 & 0 & 7 & 0 \\
\hline
\end{tabular}

${ }^{\star} \mathrm{N}=$ normal, $\mathrm{A}=$ affected, $\mathrm{U}=$ unknown status.

We used a segregation analysis based on the so called mixed model, which incorporates Mendelian inheritance of a single major gene locus, non-Mendelian polygenic inheritance, and transmissible or non-transmissible environmental factors. The model assumes that the liability to the disease can be described by an underlying continuous liability scale (y). The liability of each person is assumed to be determined by the independent contribution of a major locus (g) (a locus that causes a displacement of more than one phenotypic standard deviation between normal and abnormal genotypes on the liability scale); a multifactorial component (c), attributable in theory to a large number of genetic or environmental influences, or both, acting additively and transmitted from parents to their children; and a random, non-transmitted environmental factor (e). The individual liability to disease in this model is then $y=g+c+e$. The variance $(V)$ of $y$ is similarly divided into three components: $\mathrm{V}=\mathrm{G}+\mathrm{C}+\mathrm{E}$, where $G, C$, and $E$ are the variances of $g$, $c$, and $e$ respectively. The relative contribution of multifactorial transmission is defined by $\mathrm{H}$, the heritability (in the narrow sense), which reflects genetic transmission not ascribed to a major gene and cultural transmission: $\mathrm{H}=\mathrm{C} / \mathrm{V}$. If $\mathrm{Z}$ is a parameter that takes intergenerational differences in heritability into account then $\mathrm{HZ}$ denotes the parental heritability.

The major locus, which is assumed to have two alleles- $A$ and $A^{\prime}$ producing three genotypes $A A$, $\mathrm{AA}^{\prime}, \mathrm{A}^{\prime} \mathrm{A}^{\prime}$ - is defined by three parameters: $\mathrm{q}$, the frequency of the major gene $A^{\prime} ; t$, the displacementthat is, the distance measured in standard deviations on the liability scale between the two homozygous genotype class means; and $\mathrm{d}$, the degree of dominance, expressed as the position of the heterozygous class mean in relation to the homozygous class mean $(d=0$ corresponds to a recessive gene, $d=1$ to a dominant gene, and $\mathrm{d}=0.5$ to an additive gene).

The affected state is defined by a threshold $(T)$ on the liability scale, which is determined from the morbid risk of disease. For inflammatory bowel disease the morbid risk varies with age. Hence each person was assigned to a liability class based on age. The program used allowed for only nine different liability classes. Six classes were used for ulcerative colitis (table II).

TABLE II-Liability classes for patients with ulcerative colitis or Crohn's disease used in computer analysis

\begin{tabular}{lccc}
\hline & & \multicolumn{2}{c}{ Morbid risk $\left(\times 10^{\circ}\right)$} \\
\cline { 3 - 4 } $\begin{array}{l}\text { Liability } \\
\text { class }\end{array}$ & Age (years) & Ulcerative colitis & Crohn's disease \\
\hline 1 & $8-19$ & 208 & 122 \\
2 & $20-29$ & 2405 & 688 \\
3 & $30-39$ & 2340 & 841 \\
4 & $40-49$ & 2419 & 734 \\
5 & $50-59$ & 1990 & 718 \\
6 & $\geqslant 60$ & & 485 \\
7 & Died 1940-60 aged 0-40 & 25 \\
8 & Died 1940-60 aged $\geqslant 40$ & & 35 \\
9 & Died 1961-80 aged $\geqslant 40$ & & \\
\hline
\end{tabular}

For Crohn's disease, which has increased in frequency during the past $20-30$ years, ${ }^{89}$ an additional three classes were defined for dead subjects based on their age and year of death (table II). For the living patients and for those in the Crohn's disease group who died after 1980 the morbid risks were based on age specific prevalences obtained by concurrent epidemiological studies. ${ }^{910}$ For those in the Crohn's disease group who died before 1981 the morbid risks were derived from approximate prevalences obtained in the study conducted by Binder et al in 1962-78.

Further details of the analysis are given in the appendix.

\section{Results}

\section{ULCERATIVE COLITIS}

Table III gives the results of the complex segregation analyses for ulcerative colitis. The sporadic modelthat is, the model not including any family resemblance $(\mathrm{H}=\mathrm{q}=0)$ - gave a poor fit compared with the multifactorial model $(H>0)\left(\chi^{2}=60 \cdot 52-(-30 \cdot 81)=\right.$ 91.33; $p<0.001)$. There was no evidence of an intergenerational difference $(Z=0.67)$ for multifactorial heritability $\left(x^{2}=-30.81-(-31 \cdot 67)=0.86\right)$. Among the three models that incorporated a major locus $(q>0)$ the recessive model $(\mathrm{d}=0)$ did not explain the observed segregation pattern as well as the dominant model $\left(\chi^{2}=2.42\right.$ for the recessive model, $\chi^{2}=15.21, p<0.005$ 
for the dominant model). The additive model $(d=0.5)$ yielded an equivalent likelihood to that of the dominant model $(\mathrm{d}=1)$ with corresponding estimated parameters (same $\mathrm{q}$, and $\mathrm{t}$ of the dominant model equals $t \times d$ of the additive model). This was due to the low frequency of the susceptibility allele $\left(43 \times 10^{-5}\right)$ and the resulting low probability that any of the affected patients were homozygous. In fact, no families had both parents affected (table I). There was no evidence for an additional transmissible multifactorial component since $\mathrm{H}$ always went to zero when iterating all parameters.

Table IV gives the characteristics of the major dominant locus for ulcerative colitis by liability class. The penetrance (probability of having the disease for given genotype expressed as $\mathrm{P}$ (disease/genotype)) of the abnormal allele $\mathrm{A}^{\prime}$ was almost the same for the liability classes above class 1 , being 0.26 in the

TABLE III-Results of complex segregation analysis for ulcerative colitis

\begin{tabular}{|c|c|c|c|c|c|c|}
\hline Model & Heritability & Z & $\begin{array}{c}\text { Gene } \\
\text { frequency } \\
\text { (q) }\end{array}$ & $\begin{array}{c}\text { Displacement } \\
\text { between two } \\
\text { homozygous } \\
\text { means }(t)\end{array}$ & $\begin{array}{l}\text { Degree of } \\
\text { dominance } \\
\text { (d) }\end{array}$ & $-2 \times \ln L+c$ \\
\hline Sporadic & $0^{\star}$ & - & $0^{\star}$ & - & - & $60 \cdot 52$ \\
\hline Multifactorial & 0.53 & $1^{\star}$ & $0^{\star}$ & - & - & $-30 \cdot 81$ \\
\hline \multicolumn{7}{|l|}{$\begin{array}{l}\text { Multifactorial with } \\
\text { generational }\end{array}$} \\
\hline difference & 0.57 & 0.67 & $0^{\star}$ & - & - & $-31 \cdot 67$ \\
\hline Recessive major locus & $0^{\star}$ & $1^{\star}$ & 0.048 & $2 \cdot 38$ & $0^{\star}$ & $-34 \cdot 09$ \\
\hline Additive major locus & $0^{\star}$ & $1^{\star}$ & 0.00042 & $4 \cdot 43$ & $0.5^{\star}$ & $-46 \cdot 86$ \\
\hline \multicolumn{7}{|l|}{ Dominant major } \\
\hline locus & $0^{\star}$ & $1^{\star}$ & 0.00043 & $2 \cdot 21$ & $1^{\star}$ & $-46 \cdot 88$ \\
\hline
\end{tabular}

$\mathrm{Z}=$ parameter that takes intergenerational differences in heritability into account, $\ln \mathrm{L}=$ natural logarithm of the likelihood, and $\mathrm{c}=\mathrm{a}$ constant.

${ }^{\star}$ Fixed parameter.

TABLE IV-Penetrance and contribution of the major dominant locus for each liability class of ulcerative colitis

\begin{tabular}{|c|c|c|c|c|}
\hline \multirow{2}{*}{$\begin{array}{l}\text { Liability } \\
\text { class }\end{array}$} & \multirow{2}{*}{$\begin{array}{c}\text { Age } \\
\text { (years) }\end{array}$} & \multirow{2}{*}{$\frac{\mathrm{P} \text { (disease|genotype) }}{{\mathrm{A} \mathrm{A}^{\prime} \text { or } \mathrm{A}^{\prime} \mathrm{A}^{\prime}}}$} & \multicolumn{2}{|c|}{$\mathrm{P}$ (genotype|disease) } \\
\hline & & & A A & $\mathrm{A} \mathrm{A}^{\prime}$ \\
\hline 1 & $8-19$ & 0.08 & 0.68 & 0.32 \\
\hline 2 & $20-29$ & 0.20 & 0.87 & 0.13 \\
\hline 3 & $30-39$ & 0.26 & 0.91 & 0.09 \\
\hline 4 & $40-49$ & 0.26 & 0.91 & 0.09 \\
\hline 5 & $50-59$ & 0.26 & 0.91 & 0.09 \\
\hline 6 & $60+$ & $0 \cdot 24$ & 0.90 & $0 \cdot 10$ \\
\hline
\end{tabular}

TABLE V-Results of complex segregation analysis for Crohn's disease

\begin{tabular}{|c|c|c|c|c|c|c|}
\hline Model & Heritability & Z & $\begin{array}{c}\text { Gene } \\
\text { frequency } \\
\text { (q) }\end{array}$ & $\begin{array}{c}\text { Displacement } \\
\text { between two } \\
\text { homozygous } \\
\text { means }(t)\end{array}$ & $\begin{array}{l}\text { Degree of } \\
\text { dominance } \\
\text { (d) }\end{array}$ & $-2 \times \ln L+c$ \\
\hline Sporadic & $0^{\star}$ & & $0^{\star}$ & & & $-1442 \cdot 30$ \\
\hline Multifactorial & 0.57 & $1^{\star}$ & $0^{\star}$ & & & $-1459 \cdot 35$ \\
\hline \multicolumn{7}{|l|}{$\begin{array}{l}\text { Multifactorial with } \\
\text { generational }\end{array}$} \\
\hline difference & $0 \cdot 70$ & 0.05 & $0^{\star}$ & & & -1462.63 \\
\hline Recessive major locus & $0^{\star}$ & $1^{\star}$ & 0.00589 & $5 \cdot 96$ & $0^{\star}$ & $-1465 \cdot 10$ \\
\hline Additive major locus & $0^{\star}$ & $1^{\star}$ & 0.0242 & $2 \cdot 76$ & $0 \cdot 5^{\star}$ & $-1460 \cdot 56$ \\
\hline \multicolumn{7}{|l|}{ Dominant major } \\
\hline locus & $0^{\star}$ & $1^{\star}$ & 0.00013 & $2 \cdot 43$ & $1^{\star}$ & $-1460 \cdot 21$ \\
\hline
\end{tabular}

$\mathrm{Z}=$ parameter that takes intergenerational differences in heritability into account, $1 \mathrm{~nL}=$ natural logarithm of the likelihood, $\mathrm{c}=\mathrm{a}$ constant

^Fixed parameter.

TABLE VI-Penetrance and contribution of the recessive major locus for each liability class of Crohn's diseases

\begin{tabular}{|c|c|c|c|c|c|}
\hline \multirow[b]{2}{*}{$\begin{array}{l}\text { Liability } \\
\text { class }\end{array}$} & \multirow[b]{2}{*}{$\begin{array}{c}\text { Age } \\
\text { (years) }\end{array}$} & \multirow[b]{2}{*}{$\begin{array}{c}\mathrm{P} \text { (disease|genotype) } \\
\mathbf{A}^{\prime} \mathbf{A}^{\prime}\end{array}$} & \multicolumn{3}{|c|}{$\mathbf{P}$ (genotype|disease) } \\
\hline & & & $A^{\prime} A^{\prime}$ & $A^{\prime} A$ & A A \\
\hline 1 & $8-19$ & $1 \cdot 0$ & $0 \cdot 28$ & 0.01 & 0.71 \\
\hline 2 & $20-29$ & $1 \cdot 0$ & 0.05 & 0.01 & 0.94 \\
\hline 3 & $30-39$ & $1 \cdot 0$ & 0.04 & 0.01 & 0.95 \\
\hline 4 & $40-49$ & $1 \cdot 0$ & 0.05 & 0.01 & 0.94 \\
\hline 5 & $50-59$ & $1 \cdot 0$ & 0.05 & 0.01 & 0.94 \\
\hline 6 & $60+$ & 1.0 & $0 \cdot 07$ & 0.01 & 0.92 \\
\hline 7 & Died $1940-60$ aged $0-40$ & 0.99 & 0.56 & 0.01 & 0.43 \\
\hline 8 & Died $1940-60$ aged $\geqslant 40$ & $1 \cdot 0$ & $0 \cdot 14$ & 0.01 & 0.85 \\
\hline 9 & Died $1961-80$ aged $\geqslant 40$ & $1 \cdot 0$ & $0 \cdot 10$ & 0.01 & 0.89 \\
\hline
\end{tabular}

$\mathrm{A}^{\prime}=$ abnormal allele, $\mathrm{A}=$ norinal allele. heterozygote or homozygote for the highest incidence groups. This means that by age $30-59$ a heterozygote or homozygote has a $26 \%$ risk of having ulcerative colitis. Conversely, the frequency with which disease can be attributed to the abnormal allele ( $\mathrm{P}$ (genotype|disease)) decreased with age. Before the age of $20,32 \%$ of the patients with ulcerative colitis were heterozygous or homozygous carriers of the major gene. In the higher liability classes the probability of an affected individual being heterozygous or homozygous for the major allele was about $0 \cdot 10$. This means that about $90 \%$ of the adult patients with ulcerative colitis have a normal genotype.

\section{CROHN'S DISEASE}

Table $\mathrm{V}$ shows the results of the segregation analysis for Crohn's disease. The sporadic model was definitely ruled out when compared with the multifactorial model $\left(X^{2}=17 \cdot 05\right)$. The multifactorial model tended to fit better when an intergenerational difference was included ( $\mathrm{Z}$ estimated at 0.05 , corresponding to a much lower heritability among parents $(\mathrm{ZH})$ than among offspring $(\mathrm{H})$ ), but it was not significantly better $\left(\chi^{2}=3 \cdot 28, p=0 \cdot 075\right)$. The model including a recessive major locus gave a better fit than the model including an additive or a dominant locus, but the fit was not significantly better than for the multifactorial model with or without a generational difference.

The difficulty in distinguishing between hypotheses was not surprising since only 209 families with Crohn's disease were available for analysis. If the recessive major locus model is accepted the gene frequency would be $59 \times 10^{-4}$. Under the major gene models, $\mathrm{H}$ always went to zero so no additional transmissible multifactorial component was evident.

Table VI shows the penetrance of the major gene locus in affected subjects with various genotypes by liability class derived from the model including a major recessive gene. The overall probability for a patient with Crohn's disease being homozygous for the major locus for Crohn's disease was 0.07. Before age 20, $28 \%$ of the patients were homozygous. Penetrance was almost complete for the recessive homozygote in all liability classes.

\section{Discussion}

In a previous paper we estimated that the sex and age standardised population relative risk for ulcerative colitis and Crohn's disease was about 10 among first degree relatives of probands with ulcerative colitis and Crohn's disease. ${ }^{\circ}$ The size of the relative risk strongly suggests a genetic contribution. ${ }^{11}$ Assuming genetic influences, the mode of inheritance can be investigated by segregation analysis of pedigree data.

The results of our complex segregation analysis suggest that a major dominant gene is present in about $10 \%$ of patients with ulcerative colitis. The penetrance of the dominant gene in adults was estimated at 0.26 hence the risk of disease in an adult offspring of a patient with ulcerative colitis induced by this gene may be $13 \%$.

Although the result was not significant, segregation analysis of the families with Crohn's disease suggested that a major recessive gene is present in about $7 \%$ of patients with this disease. Since the penetrance of this recessive susceptibility gene for Crohn's disease in the homozygote was almost complete, the risk of disease in a child with one parent with Crohn's disease induced by this gene and one unaffected parent is about $30 \times 10^{-4}$-namely, half the estimated gene frequency in the background population.

Thus a considerable number of cases of both ulcerative colitis and Crohn's disease are sporadic or non-genetic. This is, however, compatible with a population relative risk of 10 for family members 
because the population relative risk reflects the familial occurrence relative to the population occurrence.

\section{RESULTS OF OTHER STUDIES}

Only a few studies have included segregation analysis of family data on chronic inflammatory bowel disease. ${ }^{12-14}$ Comparison of these studies is difficult because of different patient populations. Selection bias is specially important in family studies of diseases in which only a minority of the cases have a genetic origin. We studied an unselected, regionally defined, relatively large group of thoroughly characterised patients over at least nine years. During these years the diagnosis had been corrected in 13 patients. We did not obtain data on the families of patients with inflammatory bowel disease who died between 1978 and 1987 . We believe that this was valid because the mortality rate of patients with inflammatory bowel disease did not differ from that expected in the background population; most patients died of common, age related diseases rather than inflammatory bowel disease ${ }^{1516}$; and no correlation has been found between severity of disease in probands and familial occurrence in other populations ${ }^{17}$ or in ours (unpublished data from our previous study ${ }^{6}$ ).

Among 963 patients with ulcerative colitis from the Stockholm county, Monsén et al found 65 with affected first or second degree relatives, or both. ${ }^{12}$ The pedigrees of these 65 patients were divided into 124 nuclear families and segregation analysis indicated that an additive major gene explained $11 \%$ of the total phenotypic variance. The penetrance for the heterozygote was $\mathbf{0 \cdot 2 2}$. No residual familial aggregation was found. To estimate the importance of the gene for cases of ulcerative colitis in the general population the authors stress the need for a larger dataset that is not restricted to pedigrees with more than one affected individual. However, the results of this Swedish study are similar to ours. Distinction between additive and dominant major genes is difficult when the disease is rare and the information is limited to manifest disease.

The results of our segregation analysis for Crohn's disease differ somewhat from those of Monsén et al. ${ }^{13}$ The Swedish data were again restricted to pedigrees of families with at least two affected members, of which there were 98 comprising 158 nuclear families. The segregation analysis indicated the presence of a major recessive gene, occurring with a frequency of 0.029 , which is six times the frequency we found. The prevalence of Crohn's disease in Stockholm county was $74 \times 10^{-5}$ compared with $55 \times 10^{-5}$ in the county of Copenhagen. However, the penetrance of the recessive gene for Crohn's disease in the homozygote was only $27 \%$ in the age group 30-44 years in the Swedish study. Furthermore, there was evidence for additional family resemblance either in terms of multifactorial heritability or in terms of a modifier gene.

In a German study designed more like ours except for patients being included from a referral centre, Küster et al also found evidence for a major recessive gene for Crohn's disease. ${ }^{14}$ The proportion of cases explained by presence of the gene was high if the disease had early onset; overall about $30 \%$ of cases were due to homozygosity for the susceptibility gene. This is a much higher proportion than we found.

The results of a Swedish study of twins also supported the role of a recessive gene. ${ }^{18}$ Eight of 18 monozygotic and one of 26 dizygotic twin pairs were concordant for Crohn's disease.

\section{CONCLUSIONS}

To summarise, although the model including a major recessive gene for Crohn's disease did not differ significantly from that for the multifactorial model in our patient population, we find it reasonable to believe in this model. The model gave the best fit for our data (table V) and it is the most plausible model: although the incidence of Crohn's disease has increased ${ }^{9}$ and although the disease may be underdiagnosed in older people, we believe it unlikely that the intergenerational difference in heritability should be as big as that given in the multifactorial model with generational difference (table V). Finally, the two other studies in which complex segregation analysis of family data on Crohn's disease was performed also found evidence for the recessive model.

The segregation analysis we used does not enable us to determine the genetic relation between ulcerative colitis and Crohn's disease since disease in relatives has to be defined in the same way as for probands. However, there seems to be a connection. As previously described ${ }^{6}$ we found the sex and age standardised population relative risk of Crohn's disease among first degree relatives of patients with ulcerative colitis to be 1.72 (95\% confidence interval 0.36 to 5.04$)$ and that of ulcerative colitis among first degree relatives of Crohn's disease patients to be 3.85 (1.25 to 8.98). In the Swedish series of 1048 patients with Crohn's disease $88(8.4 \%)$ had one or more relatives with Crohn's disease, $10(1 \%)$ had relatives with both Crohn's disease and ulcerative colitis, and another $42(4 \%)$ patients had a family history of ulcerative colitis only. ${ }^{5}$ Among 963 patients with ulcerative colitis $65(6 \cdot 7 \%)$ had relatives with ulcerative colitis and $11(1 \cdot 1 \%)$ had relatives with Crohn's disease. ${ }^{4}$ This co-occurrence of the diseases within families may indicate that more genes, some of which are shared, have a role in the aetiology, and some factors in the shared environment may be of significance for the expression of the diseases. Further studies are needed to elucidate this.

In conclusion, our results suggest that in $10 \%$ of patients with ulcerative colitis a dominant major gene is of aetiological importance for the development of the disease, and that about 7\% of patients with Crohn's disease are homozygous for a recessive susceptibility gene. The next step may be genetic linkage studies to determine the chromosomal location of the relevant genes.

\section{Appendix}

Complex segregation analysis was performed with the computer program POINTER. ${ }^{7}$ Nuclear families were distinguished according to whether or not they were ascertained through a pointer, which is defined as an affected patient who leads to the ascertainment of a nuclear family but who is not a member of this family.

There were 375 and 80 nuclear families ascertained through a parent affected by ulcerative colitis or Crohn's disease, respectively, which provide complete selection of the possible phenotypes among the offspring of this matching type (table I). The remaining families were ascertained through children or other relatives, resulting in incomplete selection of the possible offspring phenotypes. Incomplete selection is corrected for in the analysis by taking into account the ascertainment probability ( $\Pi$ ) which is defined as the probability that an affected individual is a proband. It may be estimated from the proportion of probands among affected siblings of each proband $(\Pi=\Sigma \mathrm{a}(\mathrm{a}-1) / \Sigma \mathrm{a}(\mathrm{r}-1)$, where $\mathrm{a}$ is the number of independently ascertained probands and $r$ the total number of affected siblings within the sibships). $\Pi$ was estimated at 0.26 for ulcerative colitis families. For Crohn's disease, there was only one proband in each nuclear family, corresponding to a $\Pi$ of 0 , but for the purpose of the analysis it was set to $0 \cdot 001$.

All the parameters of the model were estimated by maximising the overall likelihood. To test the hypotheses, the relevant parameters were held constant while estimating the remaining parameters. The value reported was $-2 \ln L+c$, where $\operatorname{lnL}$ is the natural logarithm of the likelihood and $\mathrm{c}$ is a constant. The difference between the values of $-2 \ln L+c$ under the general model (with $\mathrm{m}$ parameters) and under 
a reduced model (with $\mathrm{k}$ parameters) is asymptotically distributed as a $\chi^{2}$ with $\mathrm{m}-\mathrm{k}$ degrees of freedom.

1 McConnell RB. Inflammatory bowel disease: newer views of genetic influence. In: Berk JE, ed. Developments in digestive diseases. Philadelphia: Lea and Febiger, 1980:129-37.

2 Farmer RG, Michener WM, Mortimer EA. Studies of family history among patients with inflammatory bowel disease. Clin Gastroenterol 1980;9:271-8.

3 Lashner BA, Evans AA, Kirsner JB, Hanauer SB. Prevalence and incidence of inflammatory bowel disease in family members. Gastroenterology 1986;91: 1396-400.

4 Monsén U, Broström O, Nordenvall B, Sörstad J, Hellers G. Prevalence of inflammatory bowel disease among relatives of patients with ulcerative colitis. Scand f Gastroenterol 1987;22:214-8.

5 Monsén U, Bernell O, Johansson C, Hellers G. Prevalence of inflammatory bowel disease among relatives of patients with Crohn's disease. Scand $\mathcal{f}$ Gastroenterol 1991;26:302-6.

6 Orholm M, Munkholm P, Langholz E, Nielsen OH, Sørensen TIA, Binder V. Familial occurrence of inflammatory bowel disease. N Engl f Med 1991;324: $84-8$

7 Lalouel JM, Morton NE. Complex segregation analysis with pointers. Hum Hered 1981;31:312-21.

8 Binder V, Both H, Hansen PK, Hendriksen C, Kreiner S, Torp-Pedersen K. Incidence and prevalence of ulcerative colitis and Crohn's disease in the county of Copenhagen, 1962 to 1978 . Gastroenterology 1982;83:563-8.

9 Munkholm P, Langholz E, Nielsen OH, Kreiner S, Binder V. Incidence and prevalence of Crohn's disease in the county of Copenhagen, 1962-87: a sixfold increase in incidence. Scand 7 Gastroenterol 1992;27: $609-14$
10 Langholz E, Munkholm P, Nielsen OH, Kreiner S, Binder V. Incidence and prevalence of ulcerative colitis in Copenhagen county from 1962 to 1987. Scand f Gastroenterol 1991;26:1247-56.

11 Khoury MJ, Beaty TH, Liang K-Y. Can familial aggregation of disease be explained by familial aggregation of environmental risk factors? Am I Epidemiol 1988;127:674-83

12 Monsén U, Iselius L, Johansson C, Hellers G. Evidence for a major additive gene in ulcerative colitis. Clin Genet 1989;36:411-4.

3 Monsén U. Inflammatory bowel disease. An epidemiological and genetic study [thesis]. Stockholm: Carolinska Medico Chirurgiska Institutet, 1990.

14 Küster W, Pascoe L, Purrmann J, Funk S, Majewski F. The genetics of Crohn disease: complex segregation analysis of a family study with 265 patients with Crohn disease and 5,387 relatives. Am J Med Genet 1989;32:105-8.

15 Binder V, Hendriksen C, Kreiner S. Prognosis in Crohn's disease-based on results from a regional patient group from the county of Copenhagen. Gut 1985;26:146-50.

16 Hendriksen C, Kreiner S, Binder V. Long term prognosis in ulcerative colitis-based on results from a regional patient group from the county of Copenhagen. Gut 1985;26:158-63.

17 McConnell RB, Shaw JM, Whibley EJ, McConnell TH. Inflammatory bowel disease: a review of previous genetic studies and the Liverpool family data. In: McConnell R, Rozen P, Langman M, Gilar T, eds. The genetics and epidemiology of inflammatory bowel disease. Vol 11. Frontiers of gastrointestinal research. Basle: Karger, 1986:1-1

18 Tysk C, Lindberg E, Järnerot G, Flodérus-Myrhed B. Ulcerative colitis and Crohn's disease in an unselected population of monozygotic and dizygotic twins: a study of heritability and the influence of smoking. Gut 1988;29: 990-6.

(Accepted 30 October 1992)

\title{
Initiation of hypertension in utero and its amplification throughout life
}

\author{
C M Law, M de Swiet, C Osmond, P M Fayers, DJP Barker, AM Cruddas, CHD Fall
}

Abstract

Objective-To determine whether the relation between high blood pressure and low birth weight is initiated in utero or during infancy, and whether it changes with age.

Design-A longitudinal study of children and three follow up studies of adults.

Setting-Farnborough, Preston, and Hertfordshire, England, and a national sample in Britain.

Subjects -1895 children aged 0-10 years, 3240 men and women aged 36 years, 459 men and women aged 46-54 years, and 1231 men and women aged 59-71 years. The birth weight of all subjects had been recorded.

Main outcome measure-Systolic blood pressure.

Results-At all ages beyond infancy people who had lower birth weight had higher systolic blood pressure. Systolic blood pressure was not related to growth during infancy independently of birth weight. The relation between systolic pressure and birth weight became larger with increasing age so that, after current body mass was allowed for, systolic pressure at ages 64-71 years decreased by $5.2 \mathrm{~mm} \mathrm{Hg}$ $(95 \%$ confidence interval 1.8 to 8.6$)$ for every $k g$ increase in birth weight.

Conclusions-Essential hypertension is initiated in fetal life. A raised blood pressure is then amplified from infancy to old age, perhaps by a positive feedback mechanism.

\section{Introduction}

Folkow suggested that there are two components in the aetiology of essential hypertension: an initiating process raises the blood pressure, and an amplifying process progressively magnifies the difference throughout life. ${ }^{1}$ If this is true, the initiating abnormality could be difficult to detect because it would have a small effect on blood pressure in the early years of the disease. There is little evidence on whether amplification occurs in essential hypertension, though the rise in blood pressure with increasing age is consistent with this. It is clear that amplification occurs in secondary hypertension. In patients with phaeochromocytoma, Conn's syndrome, or renal artery stenosis, hyperten- sion can persist even after the primary cause, the tumour or stenosis, has been removed. ${ }^{23}$

Recent work has shown that raised blood pressure in adults is associated with reduced growth in early life..$^{45}$ Mean systolic and diastolic pressures of men and women in middle and late life fall progressively from those with the lowest birth weights to those with the highest. Blood pressure is also higher in those whose birth weights were low in relation to that expected from their placental weights. ${ }^{4}$ Children show similar relations. ${ }^{6}$ These findings could indicate that high adult blood pressure is initiated in utero. Alternatively, healthy infants of low birth weight may have accelerated growth, so called catch up growth, during the first six months of life. ${ }^{78}$ If this accelerated early growth were accompanied by an accelerated rise in blood pressure, then the values would be set on a higher than expected plane when tracking of blood pressure becomes established after 6 months of age. ${ }^{9}{ }^{10}$

We examined the timing of initiation of high blood pressure and the occurrence of amplification by bring ing together data from four studies of children and adults in Britain.

\section{Methods}

We used data from the following studies. In two of them (Farnborough and Hertfordshire) weight at 1 year of age was recorded in addition to birth weight.

\section{CHILDREN}

Farnborough-The Brompton study of blood pressure was based on 1895 consecutive term ( $\geqslant 38$ completed weeks of pregnancy) births at Farnborough Hospital, Kent, from 1975 to 1977 . The infants were followed up at 4 days, 6 weeks, 6 months, 1 year, and yearly thereafter to the age of 10 years; at each age systolic pressure and weight were measured by a standardised procedure. A $4 \mathrm{~cm}$ cuff was used at ages up to 6 months, an $8 \mathrm{~cm}$ cuff from 6 months to 8 years, and a $12 \mathrm{~cm}$ cuff on some children aged 5-8 years and all children from 8-10 years. Details of the methods and follow up rates have been published. ${ }^{9}$ We excluded two children born at more than 42 completed weeks of pregnancy. 